\title{
Making Sense of Vicarious Responsibility: Moral Philosophy Meets Legal Theory
}

\author{
Daniela Glavaničová ${ }^{1,2}$ ( Matteo Pascucci ${ }^{2}$ (D)
}

Received: 16 February 2021 / Accepted: 9 February 2022

(c) The Author(s) 2022

\begin{abstract}
Vicarious responsibility is a notoriously puzzling notion in normative reasoning. In this article we will explore two fundamental issues, which we will call the "explication problem" and the "justification problem". The former issue concerns how vicarious responsibility can plausibly be defined in terms of other normative concepts. The latter issue concerns how ascriptions of vicarious responsibility can be justified. We will address these two problems by combining ideas taken from legal theory and moral philosophy. Our analysis will emphasise the importance of the voluntary involvement of the normative parties considered liable in a relation with other normative parties who causally contributed to a prohibited state-of-affairs.
\end{abstract}

\section{Introduction}

An individual is sometimes regarded as responsible for something that does not depend (solely) on their own conduct. Examples of this phenomenon can easily be found in many contexts: an employer may be held responsible for an employee's tort; an owner of a vehicle for the negligence of the vehicle's driver; a member of a group for the actions of other group members; parents for the wrongdoings of their children, and so forth. While only the first item on this list is an uncontroversial instance of vicarious liability as a legal doctrine (and the rest are perhaps rooted in agency law), a common idea runs through each of them: one party is held responsible for another party's actions. Moreover, this idea is common not only in legal, but also in moral practice. In the present paper, we will understand vicarious responsibility in

Daniela Glavaničová

daniela.glavanicova@gmail.com

Matteo Pascucci

matteopascucci.academia@gmail.com

1 Department of Logic and Methodology of Sciences, Faculty of Arts, Comenius University in Bratislava, Bratislava, Slovak Republic

2 Department of Analytic Philosophy, Institute of Philosophy, Slovak Academy of Sciences, Public Research Institution, Bratislava, Slovak Republic 
this extremely broad and neutral sense: as moral or legal responsibility for another party's actions.

The concept of vicarious responsibility looks, at first glance, like a sort of contradictio in adjecto. Indeed, while we often understand responsibility as involving direct participation, the modifier vicarious seems to exclude any such participation. So, how can one reconcile the two components of this expression? We will call this the explication problem. On top of this, the confusion is increased by the fact that some defend the master's tort theory of vicarious responsibility, which has it that it is not (just) liability that is attributed to the second party, but also the action in question. In which case, vicarious responsibility would ultimately be a misnomer (Stevens 2007), perhaps based on a legal fiction (Weinrib 2012). Following Neyers (2005) and Giliker (2010), we believe that such a conclusion about vicarious responsibility is not inevitable, since it is possible to make sense of vicarious responsibility without attributing actions to parties who have not performed them.

In addition, vicarious responsibility gives rise to the justification problem: how is it possible to justify the idea that a normative party $A$ is responsible for the misdeeds of another normative party $B$, when $A$ would have been considered faultless if the result of their own conduct had been the only thing under evaluation? In other words, how is it possible to ascribe responsibility without any obviously relevant prior exercise of agency on the part of the persons charged, if we want to guarantee a fair practice of responsibility ascription? Prima facie, such a practice does not appear just. As (Giliker 2010, p. xli) puts it, "vicarious liability seemed to be the cuckoo in the nest; imposing liability without fault on innocent parties (usually employers) regardless of their attempts to exercise reasonable care." To this day, vicarious liability remains a controversial but widespread doctrine in legal theory. As (Gray 2018, p. ix) perceives it, despite "a long case history reflecting such a doctrine, a satisfactory unifying rationale for the imposition of such liability remains elusive." Moreover, the currently prevailing doctrine, the enterprise risk model, has been subjected to thorough criticism by Gray, Neyers and others. In moral theory, the notion is no less problematic, albeit considerably less discussed (perhaps because the issue is practically less pressing).

The controversial nature of vicarious responsibility thus stems from two fundamental sources: the problem of its explication and the problem of its justification. The main goal of the present paper will be to address these problems. As far as the explication problem is concerned, we will draw inspiration from Cane's legal theory, supporting his general understanding of vicarious responsibility, and following his parallel treatment of responsibility ascription in law and morality. As far as the justification problem is concerned, we will draw on the indemnity theory proposed by Neyers (2005). While we disagree with some of the core features of this theory, we share the belief that liability, even if strict, should be rooted in agents' voluntary decisions. We will also employ the notion of substantive responsibility, taken from Scanlon's moral philosophy. While the present paper is entirely informal in nature, one of our aims is to propose an explication of the notion of vicarious responsibility that can be straightforwardly and meaningfully represented in a formal language (see, e.g., the logic provided in Glavaničová and Pascucci 2019 or in Oddie and Tichý 1982). 
The structure of the paper is as follows. Section 2 illustrates the phenomenon of vicarious responsibility by discussing several examples of ascribing vicarious responsibility in law and morality. Section 3 introduces the explication problem. Since this problem is of a conceptual nature-and, to our knowledge, no general solution to the problem has been offered in the literature-this section will be concerned mainly with the interplay of crucial concepts. What the problem is will thus be the main concern. Section 4 introduces the justification problem. Since this problem is of a highly practical nature and is immensely pressing for legal practice, it is not surprising that several solutions have been suggested in the literature; we will assess their strengths and weaknesses. How to overcome the problem will thus be the main concern. Section 5 introduces the crucial ingredients for our solution of the two problems: a criterion of voluntary involvement, Cane's treatment of strict liability, and Scanlon's notion of substantive responsibility. We will see that the criterion of voluntary involvement ultimately reveals the connection between the two problems. Sections 6 and 7 present our solution to the two problems. Section 8 concludes the paper and points to some directions for future research.

\section{Vicarious Responsibility in Law and Morality}

Vicarious responsibility as a legal doctrine allows for holding one party liable for another party's torts. As we indicated, the most common (and the only uncontroversial) relation that gives rise to legal vicarious responsibility is the employeremployee relation: an employer may be held responsible for their employees' wrongdoings insofar as these wrongdoings happen in the course of employment (or insofar as they fall within the scope of employment). The doctrine of vicarious responsibility keeps adapting to ever-changing conditions in society. The emergence of highly professional employees divorced vicarious responsibility from the condition of employers' control over their employees. The standard case is that of an employee's negligent manner of executing tasks that are related to their employment and executed for their employer's benefit. However, there are significant exceptions to this, which we can survey by drawing on some examples of trials mentioned by Giliker (2010).

For instance, vicarious responsibility is sometimes attributed even when the task is clearly not done for the employer's benefit, as in the case Century Insurance Co. Ltd $v$ Northern Ireland $R T B,{ }^{1}$ where the driver of a petrol lorry discarded a lighted match used for smoking while delivering petrol. The driver's action led to an explosion which damaged the tanker and other private properties nearby. The driver's action was clearly not for the employer's benefit; yet the employer was held liable. Also, misguided attempts to further employers' interests are normally covered. For example, in the case Bayley v Manchester, Sheffield and Lincolnshire Rly Co., ${ }^{2}$ a person was injured and pulled out of a railway carriage by a train porter who mistakenly believed that the passenger was on the wrong train.

\footnotetext{
1 AC 509 (1942).

2 LR 8 CP 148 (1873).
} 
An increasing need for victim protection has led to including liability not only for explicitly prohibited negligent actions of employees, but also for intentional criminal conduct. An example of the former is the case Canadian Pacific Railway Company $v$ Lockhart, ${ }^{3}$ where an employee intentionally violated an explicit prohibition against using one's own car for company business, and caused an accident while driving an uninsured personal vehicle. Examples of the latter are still controversial. In Bazley $v$ Curry, ${ }^{4}$ Lister v Hesley Hall Ltd ${ }^{5}$ and Majrowski v Guy's and St. Thomas's NHS Trust ${ }^{6}$ an employer was held vicariously responsible for the intentional wrongdoing of their employees (abuse, harassment, sexual misconduct). Moreover, the conditions of modern employment are forcing the detachment of vicarious responsibility from the idea that an employer can be held responsible only for the actions of their employees, since it proves difficult to distinguish employees from independent contractors and borrowed workers (Brodie 2006, Giliker 2010).

There are other relations that might give rise to vicarious responsibility, even though it is controversial whether they really count as instances of vicarious responsibility. Let us mention two such examples. One is the borrower-lender relation. For instance, there are cases in which the owner of a vehicle is held responsible for the negligent conduct of a driver who borrowed the vehicle. Another often discussed relation is that between a parental carer and a child they care for, which can give rise to parental responsibility. Parental carers are often asked for compensation when their child damages someone else's property. Consider the following example: a minor child Emma plays with her classmates and damages Anne's new pair of jeans. Anne's parents ask Emma's parents for compensation: they are expected to bear the consequences of Emma's action. Such an example can be perceived as an ascription of moral vicarious responsibility.

\section{The Explication Problem}

The problem of explicating vicarious responsibility is due to a deeply ingrained intuition about the connection between responsibility, fault and causal contribution (here the latter will also be called "causal participation"): in many everyday circumstances we ascribe responsibility to an individual when they causally contributed to something that is prohibited, thus being at fault for what happened. This is also reflected in debates on responsibility. For instance, Hart (1949) points out that responsibility is ascribed to an individual via sentences of the form they did it, in the same way that property rights are assigned to an individual via sentences of the form this is theirs. However, in the case of vicarious liability, as the term "vicarious" suggests, the party who is considered vicariously liable is not the party who "did it". Similarly, as (Giliker 2010, pp. 18-19) observes:

\footnotetext{
3 AC 591 (1942).

42 SCR 534 (1999).

51 AC 215 (2002).

6 UKHL 34 (2006).
} 
"Vicarious liability, as a doctrine, is thus problematic. It does not fit into the dominant concept of fault underlying the law of tort and focuses not on individual responsibility for one's actions, but on responsibility for others in the absence of proof of fault on one's part."

In order to make room for a theoretical analysis of vicarious responsibility, one should adopt a broader perspective. For instance, in Cane (2002) responsibility does not always include causal contribution as an ingredient. In accordance with this, in our opinion, a good starting point for addressing the explication problem consists in clarifying the distinction between contributory responsibility and responsibility understood as a duty to bear normative consequences (which we will here call liability). While these two notions often go hand in hand (as they do in the case of primary fault-based liability), they can also come apart from each other. For example, a minor child or an animal can break an expensive vase in a hotel (contributory responsibility), but neither of them will incur a duty to compensate (liability). We will thus distinguish the contributory party (who bears contributory responsibility) from the liable party (who bears liability, i.e., incurs a duty to bear normative consequences).

As far as contributory responsibility is concerned, we will focus here on the notion of a normatively relevant contribution rather than on the broader notion of a causally relevant contribution, given that not all forms of causal contribution are normatively relevant. This echoes the well-known distinction between causes-in-fact and proximate causes (Levitt 1922). However, by speaking of causal contribution rather than proper causation, we also aim to handle cases in which someone tries to produce a result without success, due to the intervention of others or to unexpected natural interferences (e.g., Alan attempts to rob Carl, but Brenda's last-minute intervention prevents this attempt from being effective); furthermore, the notion of causal contribution makes room for causal overdetermination (e.g., two assassins shoot at a victim and both bullets suffice to produce the tragic outcome; so each of the assassins causally contributed to the outcome and is thus responsible).

We will use the word responsibility (tout court) in a broad sense, encompassing both liability and contributory responsibility. Moreover, we will treat the expressions vicarious liability and vicarious responsibility as equivalent (noting that the former is more common than the latter in legal texts); this will allow us to provide a uniform presentation of works in the literature where either of these two expressions is used. Our main aim with respect to the explication problem will be to provide an answer to the following general question:

(Q1) How can the notion of vicarious responsibility be consistently explicated, given that liability and contributory responsibility are ascribed to different parties?

Our answer to (Q1) is formulated in detail in Sect. 6.

Another important aspect that we want to highlight is that talking about the moral domain or the legal domain seems to make a difference in explicating vicarious responsibility. Indeed, there is a stronger tendency to associate liability with contributory fault in the moral domain. The key to disclosing this difference might be 
the level of analysis of normative relations in the two domains. We take a normative relation to be any relation that holds among a finite number of subjects (either individuals or collectives), called normative parties, and which is morally or legally relevant. A normative relation establishes that the parties it involves are grouped into certain categories, which correspond to the parties' roles (e.g., employer and employee). Legal documents typically describe normative relations quite precisely, as well as the possible behaviour of each party in a relation; this information allows one to determine the sort of circumstances where a normative party is held to bear normative consequences for the misconduct of another. For instance, Article 1242 of the French Civil Code speaks of "liability of father and mother, so far as they exercise parental authority, for acts of their minor children who live with them"7 and "liability of craftsmen for their apprentices during the time when they are under their supervision" (Giliker 2010, p. 23). Here being a parent (who has a minor child living with them) or being a craftsman (who has an apprentice under their supervision) are roles that can give rise to liability. By contrast, in the moral domain the roles we happen to play are often not precisely defined, and it is therefore much more natural to consider every normative party to be responsible for their own conduct only. In other words, moral responsibility is usually understood as requiring the condition of fault, and a proper distinction between liability and contributory responsibility in the moral domain requires deeper reflection (note, however, that some defend strict moral responsibility; see, for instance, Duff 2009). Following an intriguing suggestion from Cane, we will examine how this issue can be addressed by treating vicarious responsibility in both domains as a form of liability regardless of fault.

Finally, we want to point out that there are alternative accounts of vicarious responsibility which preserve the condition of fault. For instance, as (Giliker 2010, p. 9) observes, the German law of vicarious responsibility is based on a (rebuttable) presumption that the employer is at fault. (May 1983, p. 78) claims that a corporation can be held vicariously negligent for something when both causal participation and the condition of fault are present. May is aware of the possible objection that this notion of vicarious negligence "is not vicarious liability at all, as presently conceived in legal circles", and acknowledges that "it has become commonplace to define vicarious liability as a form of strict liability, hence ruling out any negligence, or any fault condition, by definition." However, as these quotations suggest, May understands strict liability as liability in the absence of fault, rather than liability regardless of fault, whereas in the present article we will adopt the latter perspective, following Cane's approach.

\footnotetext{
7 We stress that it is not the parental role, on its own, that gives rise to this form of liability. In fact, what ultimately counts here as a crucial role for liability ascription is the exercise of parental authority, which may vary among cases. For instance, according to the laws of many countries, in the cases of illegitimate children, involuntary parenthood, etc., only one or neither of the two parents may have parental authority.
} 


\section{The Justification Problem}

In accordance with the terminology introduced in Sect. 3, the justification problem consists in showing why it is sometimes appropriate to consider a normative party to be liable for the contributory responsibility of another. Indeed, the party being held liable might be entirely faultless and, because of this, the practice of vicarious responsibility does not appear just. The seriousness of the justification problem is witnessed by the rather incoherent reasoning about vicarious responsibility seen in courts. As (Magnet 2015, p. 216) claims:

The unpredictable and illogical nature of vicarious liability, as currently utilized, is attested to as much by the extraordinary number of successful appeals as by the erratic and irreconcilable results litigation has produced. All of this indicates a tumultuous lack of consensus in the courts.

In order to address the justification problem, one has to look for a plausible answer to the following general question:

(Q2) Under which conditions it is justified to ascribe vicarious responsibility, given that the liable party can be entirely faultless?

Several options have been considered in the literature. As we will illustrate, there is considerable disagreement about what the right justification of vicarious responsibility is. Proposed justifications seem to face rather serious issues even in the context of the employer-employee relation, let alone if taken as a general justification for the broad idea of vicarious responsibility. We will discuss these justifications below by labelling the three relevant normative parties involved in a scenario as the liable party, the harmed party and the contributing party, respectively. We want to stress that if a normative party is sued for vicarious liability, they do not automatically have to bear the consequences of this (i.e., to be the liable party); indeed, they can use the evidence available to them to answer the charge. Thus, as Blatz (1972) suggests, liability is always a form of interaction between two parties: one accusing and the other giving answers. This, in our opinion, is an aspect that deserves attention in the general debate on responsibility, as well as in the debate on vicarious responsibility.

One prima facie possibility for answering (Q2) is to rely on the varying wealth of the normative parties, suggesting that the liable party has deeper pockets than the contributing party (as is usually the case in the employer-employee relation), and is thus more capable of compensating the harmed party for the harm done by the contributing party. However, this would not work in general as a justification, since, for instance, in the case of a faulty employee, there might be many other parties involved who have deeper pockets than the employer; also, there are cases where an employer is, in fact, bankrupt, and the employee is wealthy. In addition, while not a philosophical reason, it might be worth mentioning that the hypothesis that someone can be held vicariously responsible for the actions of another due to their greater ability to compensate the victim has not received empirical support (see Shultz et al. 
1987). As Gray (2018) notes, however, courts have occasionally been open about finding someone (an employer) vicariously liable due to having sufficient financial resources to compensate the victim. Gray points out that such reasoning is considered deeply unprincipled (that is, it is not applied elsewhere in the law). He also discusses the worries that such reasoning could similarly be made by any burglar, and that by harming the employer one also harms the employees, the industry and more broadly, the economy. Moreover, as noted by Neyers (2005), one cannot take it to be a general rule that the richest party among all those involved in a contract bears liability for the others' wrongdoings whenever they are unable to compensate. One reason for this is that the employer will be usually richer than their workers, whether they are employees or independent contractors. It would thus be unclear why vicarious liability should apply in the former case only. Also it is not clear how deep pockets would suffice for the imposition of liability, and what to do when the employer no longer has sufficiently deep pockets (see Gray 2018, pp. 151-153). Lastly, one could argue that the idea of building vicarious responsibility around the aim of compensating the harmed party, as in the deeper pockets approach, is inspired by liability insurance. Nevertheless, as Cane and Goudkamp (2018) remark, liability insurers differ in two important ways from vicariously liable parties: first, they have obligations towards the insured parties, rather than towards the harmed parties; second, they are not allowed to recover the amount paid under the policy from the insured. ${ }^{8}$ Given these problems, we agree with the prevailing position that such a justification is problematic.

Another possibility for answering Q2 is that the liable party has control over the contributing party. But again, this option will not suffice. For instance, reasoning in terms of an employer-employee relation, the problem is that sometimes the employee is so highly qualified that one cannot expect her actions to be controlled by her employer; yet, this does not necessarily shelter the employer from liability. As (Magnet 2015, p. 216) puts it,

The emergence of the highly specialized 'servant' has meant that, for practical purposes, the master retains a diminishing power of control over the work. This is the case with such servants as, for example, engineers, airline pilots, teachers, and doctors. Whenever vicarious liability is applied to facts involving the professional employee, the legal results are eccentric, illogical and highly uncertain.

A more promising alternative is to justify vicarious responsibility in terms of the liable party having a superior position over the contributing party, in connection with the idea of a reasonable loss distribution. While this condition of superiority would work in many cases (such as holding employers or corporations responsible for harm caused by their employees or associates), it is unclear how it would help in

\footnotetext{
${ }^{8}$ It is also worth noting that in cases in which the vicariously liable party is insured against the liability, it is the insurer who provides for compensation. However, even in that case it is still the liable party (usually the employer) who is held vicariously responsible. For this reason, these matters of insurance do not have a direct impact on vicarious responsibility, which is our focus.
} 
other cases (such as when holding individual members of a group responsible for the actions of other members of the group by imposing some punishment on the group as such; or when holding the owners of vehicles responsible for damages caused by the drivers of their vehicles).

Another option that has arisen in courts is based on evidentiary considerations. This attempt at answering Q2 is based on the idea that it can be difficult for the plaintiff (the harmed party) to put forth sufficient evidence for a successful claim against the defendant. For instance, it might be difficult for a single person to prove the negligence of a large corporation (see Murphy 2004, pp. 659-660). Typically, a large corporation can hire better lawyers and other experts (experts on legal, medi$\mathrm{cal}$, or engineering matters) to prove its innocence than any single person who is the harmed party. In such cases, it has occasionally been suggested, one can ascribe vicarious liability instead of negligence and use such evidentiary considerations as a justification. An obvious consequence is that there will be cases of assigning vicarious liability to an innocent employer. Gray notes that this approach closely resembles justifications of the reverse onus of proof "on the basis that it is difficult for a prosecution to obtain appropriate evidence, and/or it is easier for a person accused to provide evidence that they are innocent, rather than for the prosecutor to prove they are guilty" (see Gray 2018, 150). This approach, however, violates the fundamental principle "that a person who accuses another of wrongdoing must prove their allegations" (see Gray 2018, p. 150). Obviously, it is also difficult to imagine how this approach could be extended to moral instances of vicarious liability.

Deterrence is another possible justification of vicarious responsibility. For example, if an employer is held liable for their employees' torts, the employer will be encouraged to do everything in their power to prevent their employees from committing torts. However, as (Stevens 2007, p. 258) objects, "this argument fails to explain why the employer is liable even where he has taken due care in these matters."

Another option is that ascribing vicarious responsibility can be said to be fair, just, and reasonable according to a judge's opinion. While this option could be extended to cover the realm of morality, it is hopelessly circular or at least very subjective. As (Gray 2018, p. 156) puts it, "we risk dissolving the law of tort into idiosyncratic, subjective and arbitrary judgements when we make decisions about vicarious liability based on one judge's idea of fairness and justice in a particular case. Fairness and justice are in the eye of the beholder." While not everyone would agree that justice and fairness are subjective to this extent, it seems undoubtedly questionable to justify vicarious liability in terms of unclear notions that are themselves the subjects of philosophical controversies. Apart from the subjectivity, the circularity worry is pressing too: it is of little help to say that some practice is just (fair, reasonable) because it is just (fair, reasonable), unless one of these notions is independently and uncontroversially justified.

Enterprise liability (or enterprise risk theory) is most likely the prevailing approach in case law. This justification was used in Bazley $v$ Curry and was defended as a viable option by Brodie. As (Brodie 2007, p. 496) puts it, "Bazley holds that enterprise liability justifies the doctrine of vicarious liability because, on grounds of equity, an enterprise should compensate when risks it has introduced materialise. Equity also demands that the enterprise must accept full responsibility 
for managing those risks." According to the enterprise risk approach, "a particular enterprise should have costs allocated to it that fairly reflect the cost of it doing the business. [...] An enterprise should be liable for the costs it causes" (Gray 2018, p. 111). Accordingly, if too many costs are allocated, the enterprise produces less than it should; if too few costs are allocated, it produces more than it should. The goal is to allocate the appropriate amount of costs, so the enterprise is efficient. The model is based on the idea of distributive justice (as opposed to corrective or retributive justice). As (Gray 2018, p. 107) puts it, the model resorts "to principles of economics as justification for the law recognising that a wrong has been committed, as opposed to notions of fault and moral blameworthiness of conduct." Gray is highly critical of this approach. He concludes his argumentation as follows (Gray 2018, p. 187):

it has little historical support in the case law, demonstrably does not explain significant features of vicarious liability, relies on ambiguous concepts, is difficult to apply to the non-profit sector, and is just not the way in which the common law typically deals with the legal liability of a business organisation. It becomes incoherent when it simultaneously claims both a deterrent effect and a loss distribution effect.

Significant unexplained features are the inability to draw a distinction between employees and independent contractors (that is, why should the employer not be vicariously liable for independent contractors?), and the inability to explain why vicarious liability requires proof that the employee committed a tort and why the employer is allowed to claim indemnity from the employee who caused the loss. Moreover, it is doubtful whether the approach fits the condition of the scope of employment, which is traditionally perceived as crucial for vicarious liability (see Gray 2018, p. 138). Concepts of hazardous risk and business risk are ambiguous. Concerning the non-profit sector, such as residential homes, Gray notes that while there are risks of child abuse in such homes, the situation would be much worse if children were left on the streets (Brodie 2007, pp. 500-501, seems to be aware of these difficulties); so imposing liability on such institutions could result in a deterrence against operating them (rather than a deterrence against abusing children). More generally, deterrence against operating an organisation can undermine the loss distribution (some services and products will not be provided if the organisation ceases to exist).

Gray's preferred approach is the agency model (Gray 2018, p. 187),

[i]t is sound to make an employer liable for what an employee did for their purposes and benefit because the actions were authorised, expressly or implicitly, by the employer. The law either sees that the employee's actions are those of the employer, or what is preferred [...], the law says that the employer is liable for the actions of the employee as if they were the employer's actions.

We share Gray's preference between the two options, since the former seems to be a variant of master's tort theory, which is problematic for several reasons. To begin with, such an approach could elicit the objection that we are no longer 
dealing with vicarious liability but rather with personal, primary liability. (Giliker 2010, p. 15) lists three core problems with master's tort theory:

(i) any attribution of an action to a party who has not performed it is a legal fiction, and legal fictions should be discouraged whenever possible;

(ii) the notion of individual responsibility is blurred: "Primary liability exists for one's own wrongdoing. Secondary liability logically represents liability for the acts of others. The 'master's tort' doctrine fits naturally within neither category and thereby undermines the clarity of tort law in general."

(iii) a level of accountability is lost by holding only the master responsible.

Let us also note that master's tort theory does not fit very well with non-legal cases of vicarious responsibility, nor with some legal cases that do not concern employers and employees. At the very core of the problem is the fact that authorisation, which is a key ingredient of the employer-employee relation in master's tort theory, does not seem to be a necessary condition for ascribing vicarious liability: parents might not authorise some wrongdoing but still bear moral vicarious liability to compensate the harmed party; the owner of a vehicle might not authorise negligent driving but still bear legal vicarious liability.

(Neyers (2005), p. 301) proposes indemnity theory as a justification of vicarious responsibility:

a compelling justification for the doctrine can be found in the relationship between the employer and employee - namely in the employer's implied promise in the contract of employment to indemnify the employee for harms (including legal liability) suffered by the employee in the conduct of the employer's business.

Thus, according to Neyers, the employee has an indemnity right against the employer with respect to certain kinds of harm that may occur in the course of employment, and this right is granted by the contract they stipulated. How the doctrine of vicarious responsibility works in practice would then be a shortcut via a transfer of the indemnity right: instead of the harmed party suing the employee (the contributing party), followed by the employee suing the employer for indemnity, the harmed party receives from the employee their indemnity right and directly sues the employer (who is then treated as the liable party). Neyers anticipates four possible objections to this approach and responds to them: first, the theory conflicts with cases where a faultless employer successfully sues their employee for indemnity (rather than the other way around); secondly, if the doctrine is based on an implied promise in the contract of employment, then employers, due to the freedom of contracts, could agree with their employees to exclude any such right to indemnity from the stipulated contract; thirdly, the theory does not sit well with vicarious responsibility for employees' intentional torts; fourth, the theory cannot account for non-contractual cases of vicarious responsibility. The strategy employed by Neyers in responding to these worries is to argue either (in response to the first and third objection) that the problematic cases are wrongly decided, or (in response to the second objection) that it is in the very nature of an employment contract that it contains 
a promise to indemnify, or (in response to the third and fourth objection) that they constitute cases of personal, rather than vicarious, responsibility.

We would like to note that we are rather sympathetic to the gist of Neyers's approach, even though we disagree on certain elements of his theory and we take its range of application to be too narrow. We share Neyers's view that the key to the justification problem lies in the relationship between the contributing party and the liable party, rather than in the relationship between the liable party and the harmed party (as various policy justifications would suggest), and that it should be possible to trace an ascription of liability back to some decision of the liable party. However, we consider the postulation of indemnity rights restricted to certain kinds of conduct to be unnecessary for ascriptions of vicarious liability. In fact, cases where an employer is held vicariously responsible for their employees' intentional torts are increasingly common. While we do not wish to make any claim as to whether that should be so, it seems theoretically desirable for a theory of vicarious responsibility to be able to cover these cases as well. Furthermore, indemnity rights are sometimes not specified within a contract, so Neyers's approach ultimately has to bring in an element that is not always traceable. In the next section, we will make use of this insight, and highlight the importance of the liable party's voluntary involvement. This criterion will allow us to cover a wider range of cases than those covered by Neyers's indemnity theory.

\section{The Conceptual Framework: Voluntary Involvement, Strict Liability, and Substantive Responsibility}

Given the limits observed in Sect. 4, it appears that none of the proposed criteria can generally justify our practice of ascribing vicarious responsibility, broadly understood. Therefore, we need to look for a more effective and more general criterion. In this section, we will put together conceptual tools that will allow us to provide answers to our central questions Q1 and Q2, which will amount to solving the two central problems. In particular, we will focus on three ideas:

- a criterion of voluntary involvement as necessary for a fair ascription of vicarious responsibility;

- Cane's understanding of strict liability, of which vicarious responsibility is a subcategory; and

- (a broadened variant of) Scanlon's notion of substantive responsibility, and its relevance for vicarious responsibility.

It is submitted that the liable party's voluntary involvement in a certain kind of relation with the contributing party is always present whenever the practice of ascribing vicarious responsibility can be considered fair. Such a relation can be, for instance, an agreement, a contract, or an activity involving the two parties. When a person $A$ hires a person $B$, the former voluntarily gets involved in an employer-employee relation with the latter; when $A$ lends their car to $B$, they voluntarily give rise to a 
lender-borrower relation. More controversially, we believe that voluntary involvement is also a crucial component of parental responsibility. While becoming a parent need not be voluntary, becoming a parental carer usually is. Examples where one becomes an involuntary parental carer are somewhat rare and unusual. ${ }^{9}$

Entering in relations of these kinds may have relevant consequences for responsibility. In fact, there can be a form of responsibility allocation to one party for certain possible behaviours of the other party. Our approach to the justification problemand subsequently to the explication problem-will thus consist in taking the following perspective: one party takes the burden of liability for what may result from another party's contribution within the scope of the relation they enter into.

However, recall the abovementioned second objection to Neyers's indemnity theory. It seems that a parallel issue arises with the proposed criterion of voluntary involvement: can a party limit the scope of their liability? More specifically, can they limit the scope of their liability by means of a clause in a contract, or a notice that they will not accept vicarious responsibility for certain kinds of actions? Concerning the former, more general question, a party can limit the scope of their liability by choosing an alternative relation with the contributing party. As Neyers notes, an employer can hire someone as an independent contractor instead of as an employee. Concerning the latter question, the answer depends on the relation at issue: on the one hand, liability does not seem to be avoidable in general via a clause (mainly when the clause does not sit well with the given relation); on the other hand, it might be possible to avoid it under specific circumstances via exemption clauses, whose plausibility has to be assessed by a court. ${ }^{10}$

Another conceptual ingredient that will be important for our analysis of vicarious responsibility is Cane's analysis of the notion of strict liability. He understands this as liability regardless of fault, rather than liability in the absence of fault, and distinguishes various types of strict liability. In the case of vicarious responsibility, strict liability is qualified as activity-based and relational. Transposing his account into the terminology adopted here, this means that the relevant form of liability is:

(i) strict, since it does not depend on the liable party's contributory responsibility;

(ii) relational, since it depends on a connection between two normative parties (the liable party and the contributing party); and

(iii) activity-based, since it is ascribed on the basis of the activities of the liable party and the contributing party (as opposed, e.g., to outcome-based liability, which is ascribed on the basis of states-of-affairs only).

Another important issue considered by (Cane 2002, p. 175) is that when we ascribe vicarious responsibility we acknowledge that we are making reference to a form of

\footnotetext{
9 The point can be illustrated with a fictional example from the film Vivarium (a couple get involved in a relation with a child, but involuntary so), or with the following real-life example: https://www.bbc.co.uk/ news/resources/idt-sh/surrogates.

${ }^{10}$ We thank an anonymous referee for pressing us on this important point.
} 
liability shared by two parties, although finding an appropriate explanation of this aspect is not obvious:

Vicarious liability involves holding one person $(A)$ liable for breach of the law by another person $(B)$. It is a form of shared liability $-A$ shares liability with $B$. In the typical case, $B$ 's personal liability will be responsibility-based. But in such cases, is $A$ 's vicarious liability responsibility-based or is it a form of liability without responsibility?

This is a natural question and reminds us of the contradictio in adjecto mentioned in Sect. 1. Cane suggests that defining vicarious responsibility as a relational and activity-based form of strict liability allows one to solve the puzzle. ${ }^{11}$ The role played by the term activity-based emerges in the analysis of a typical case of vicarious responsibility, namely when something normatively untoward is brought about by an employee of a company. In this case the working regulation normally includes a rule to the effect that vicarious responsibility attaches to the employer only for the employee's conduct in the course of employment. As (Cane 2002, p. 76) points out, this rule

can be given a causal interpretation as a principle of causal responsibility relevant to determining when an opportunity will be treated as having been provided by the employer. [...V]iewed as a form of activity-based responsibility, it seems to rest on a principle to the effect that those who employ others to further their own projects should bear the cost of breaches of the law for the occurrence of which that employment provides the opportunity.

Important remarks on vicarious responsibility can be also found in (Cane 2016, p. 285), where this notion is discussed in connection with role responsibility:

The liability of an employer to a third party for torts committed by an employee is based not on an assumption that the employer could or should have controlled the employee but merely on the contractual relationship between them, which gives the employer (limited) legal authority over the employee. This authority does not, itself, enable (or entitle) the employer to control the employee but is, nevertheless, taken to justify imposing liability on the employer for torts of the employee regardless of capacity to control. On the other hand, if the employer could and should have exercised relevant control, the employer may be held personally liable for the injury caused by the employee's tort (as well as vicariously liable for the employee's tort).

Here Cane construes vicarious responsibility as based on the contractual relationship between the employer and the employee and the limited authority of the former over the latter. Importantly, this notion of authority does not require the idea

\footnotetext{
11 Cane also notes that one can be both personally and vicariously responsible (Cane 2002, p. 153). For instance, someone can be injured in an accident involving an employee's use of a tool, which was itself in bad condition. In that case, the employer can be both vicariously responsible and personally responsible for the injury.
} 
of control, which, as we have noted, is arguably problematic. Cane instead claims that in cases in which the employer's control over the employee can be expected and something goes wrong, personal liability comes into play as well.

Following (Cane 2002, p. 176), we believe that vicarious responsibility (while considerably less discussed in moral philosophy than in legal theory) is common also in our moral practice:

Because vicarious liability is strict and relates to the conduct of another, it is sometimes invoked as a prime illustration of the gap between legal and moral responsibility. This is a mistake. The basic idea of vicarious liability is found in the moral domain as well as in the legal. Indeed, the scope of the moral analogue of vicarious liability seems wider than its legal counterpart. For instance, in law parents are not vicariously liable for their children's torts. By contrast, in some cases, at least, it is thought right for parents to repair harm done by their children.

Indeed, moral parental responsibility is a widespread phenomenon. While legal parental responsibility exists in many jurisdictions, it is normally not the law that settles the compensation, but rather morality. To illustrate the point, consider the jeans example of parental responsibility discussed in Sect. 2.

In order to tackle moral vicarious responsibility, we will employ the notion of substantive responsibility taken from Thomas Scanlon's theory of moral responsibility. Scanlon distinguishes two important forms of moral responsibility: substantive responsibility and responsibility as attributability. Judgements of substantive responsibility express substantive claims about what we are required to do for each other; responsibility as attributability pertains to cases when an action can be attributed to someone in the sense required to make a moral appraisal (whether it is positive, negative, or even neutral) (see Scanlon 1998, pp. 248-249).

Later on, he revises the notion of responsibility as attributability and calls it moral reaction responsibility. One reason for this revision is that, in his view, both notions should ultimately be characterised in the same manner (to be two properly contrasting categories), and Scanlon opts for an opposition in terms of moral consequences. While substantive responsibility is already characterised in this way, responsibility as attributability is characterised in terms of a condition (rather than the normative consequences at issue). Moral reaction responsibility is thus intended to play the role of the proper contrasting category (see Scanlon 2015, p. 89).

While in the case of moral reaction responsibility the action has to be attributable to the agent in the sense relevant for moral appraisal, substantive responsibility does not require this (see Scanlon 1998). For this reason, obviously, we will focus on substantive responsibility. Judgements of substantive responsibility concern substantive conclusions about what we owe to each other. These obligations to others and our claims against them depend on the opportunities to choose that we have had and the decisions that we have made (Scanlon 1998, pp. 290 and 248). (Scanlon 2015, p. 109) explains substantive responsibility in a similar manner: "What individuals are (substantively) responsible for-i.e., cannot complain of - are the results of choices they make under conditions of the right kind." 
Importantly, Scanlon argues that the two notions of responsibility do not stand or fall together. He discusses interesting confusions in a political argument. For instance, a drug addict can be criticised as long as the wrong action is their own (moral reaction responsibility can be ascribed), but probably should not be left to themselves, devoid of any help (substantive responsibility perhaps should not be ascribed). In political arguments, the two notions are often conflated. This is relevant also for our purposes: in the case of ascribing vicarious responsibility, the liable party is responsible in the sense of bearing substantive responsibility, but need not be responsible in the moral reaction sense. The contributing party is often responsible in the moral reaction sense, but does not bear (full) substantive responsibility.

A remaining complication is that both of these notions are notions of moral philosophy, and it is not immediately clear whether they can be transposed to the legal context. We already anticipated broadening the notion of substantive responsibility in our understanding of liability (we used the term normative consequences, which is broader than moral consequences, as the former term covers both legal and moral consequences alike). We can similarly broaden moral reaction responsibility to legal reaction responsibility: for instance, just as one can be criticised for violating moral norms, one can be criticised for violating legal norms.

\section{Vicarious Responsibility Explicated}

Putting together the conceptual ingredients from the preceding section, we will attempt to clarify the notion of vicarious responsibility in a way that turns out to be plausible in a wide range of contexts. We will thus show how it is possible to make sense of this notoriously problematic notion in a theoretical framework.

Recall that Cane understands vicarious liability in the legal domain as holding one party liable for a breach of the law by another party. This brief specification includes several important elements. First, it mentions two parties who are somehow interrelated. Second, one party is held liable for something to which the other party causally contributed. We will say that the latter party contributed to bringing about a certain state-of-affairs. In this regard, we will also assume, for the sake of simplicity, that the notion of causal contribution has a very broad meaning, so as to allow ourselves to treat omissions as a limit case of causal contributions: an omission to bring about a state-of-affairs described by a proposition $P$ can be equated, for our purposes, with a causal contribution to bring about a state-of-affairs whose description entails the negation of $P$. (For instance, not providing aid to someone involved in a traffic collision contributes to bringing about a state-of-affairs where that person's health is worse. $)^{12}$

\footnotetext{
12 Propositions are here descriptions of states-of-affairs; thus, we use the term proposition and the term state(-of-affairs) interchangeably. We focus on responsibility with reference to states rather than with reference to actions, adhering to the philosophical stance that the performance of a certain action by a subject $A$ corresponds to the description of a state-of-affairs in which that action is performed by $A$. For instance, on this view, one could translate the claim "Anne is responsible for the murder of Mr. Boyle" into the claim "Anne is responsible for the fact that Mr. Boyle was murdered". Nevertheless, drawing a distinction between action performances and states-of-affairs would not affect the framework proposed.
} 
Additional remarks are due on the kinds of parties involved in ascriptions of vicarious responsibility. A party can be a human being, but also a non-human entity, such as an animal or a corporation. Furthermore, for the sake of concision, we will hereafter say that parties "bring about a proposition $P$ " rather than "bring about a state-of-affairs described by proposition $P$ " and that they are "responsible for $P$ " rather than "responsible for a state-of-affairs described by $P$ ". Note also that, in light of the other choices we have made, speaking of propositions and states-of-affairs has an advantage over speaking of actions and conduct, since the latter two expressions generally do not work well in relation to non-human agents.

We will take a proposition $P$, for which one party is liable and to which the other contributed, as describing a state-of-affairs that is (legally or morally) prohibited. We add to Cane's account the idea that the liable party was in a sense voluntarily involved in a relation with the contributing party and that such a relation implicitly specifies a set of undesired states-of-affairs for which the liable party is answerable (e.g., an employer and an employee stipulated a working agreement which says that the employer is answerable for her employees' failure to comply with deadlines). Putting all these elements together, we will explicate the notion of vicarious responsibility as follows:

\section{Vicarious Responsibility}

A normative party $A$ is vicariously responsible for a proposition $P$ if and only if

- (i) $P$ instantiates a prohibited proposition in a set $X$;

- (ii) an entity $B$ causally participated in bringing about $P$;

- (iii) $A$ is voluntarily involved in a relation $R$ with $B$;

- (iv) the set $X$ falls within the scope of the relation $R$.

Two additional remarks on this definition will help to clarify its range of application. First, let us stress once more that we are restricting our analysis to responsibility for the violation of a prohibition. Thus we will say that we are making reference to ascribing responsibility in the negative sense. This stands in contrast to ascribing responsibility in the positive sense, which concerns cases where a party complies with an obligation (e.g., by performing a task allocated to them). In accordance with this, in our definition of vicarious responsibility, $X$ can be regarded as a set of propositions describing general kinds of states that are prohibited within the scope of $R$. For instance, if Bertie smashes the window of a pub in his free time, this action does not count as falling within the scope of being employed by the University of York as a researcher. However, if he negligently leaks his students' personal data, this counts as falling within the scope of his employment. (Of course, there might be disagreement on the proper placement of many particular cases: for example, if Bertie harasses a student, or expresses 
extremist political views on social media, does this fall within the scope of his employment?) We take it that vicarious responsibility in the negative sense is more pressing than vicarious responsibility in the positive sense. For instance, it seems that if an employee harms someone in the course of the former's employment, it can be very important for the employer to compensate the victim. In comparison, if the employee does something praiseworthy in the scope of their employment, it is not always desirable for the praise to attach to the employer. (And it is even less desirable for it to attach only to the employer.) However, this seeming disparity might be due to a difference between good and supererogatory conduct. (That is, it is fair to praise an employer for the well-done tasks of their employees; but perhaps the employer should not be credited for the supererogatory conduct of their employees.)

In order for our definition to be applicable to a scenario, at least one of the general states in $X$ has to be instantiated by the specific state described by proposition $P$, as clause (i) suggests, and $X$ has to be relevant for the relation $R$, as clause (iv) suggests. To give an example, let $R$ be the relation holding between a pet and its owner, and let $A$ stand for Andrew, $B$ for Bailey (Andrew's cat) and $C$ for Colin (Andrew's neighbour); $X$ includes a proposition $Q$ denoting the prohibited state that one's pet harms other people, and $P$ denotes the specific state in which Bailey bites Colin in his garden on 15 October, 2020. $P$ entails $Q$ and, thus, that Andrew is vicariously liable for the outcome of his cat's behaviour. The advantage of distinguishing between the specific proposition used to ascribe responsibility, $P$, and a set of general propositions $X$ within the scope of $R$, is the following: $X$ can be fully specified in advance when $A$ takes part in a relation $R$ with $B$. For instance, $X$ can be the content of a written agreement between the two parties, and written agreements typically talk about general prohibitions that can be instantiated.

In sum, the proposed analysis of vicarious responsibility addresses the explication problem by showing that the two elements, vicarious and responsibility need not clash with each other. We have done this in terms of Cane's analysis of vicarious responsibility as a subspecies of strict liability, and the latter as liability regardless of fault. Vicarious responsibility is thus a kind of responsibility, and while the liable party is not responsible in the contributory sense, their involvement is essential.

\section{Vicarious Responsibility Justified}

In this section we will explain how the analysis of vicarious responsibility presented in the preceding section (and thus our solution to the explication problem) can help to overcome the justification problem with respect to a broad range of examples discussed in Sect. 2. Here we would like to note that we will not attempt to make a material claim as to whether vicarious responsibility should apply in a particular example or not. We rather wish to show that our analysis can in principle cover a broad variety of examples that are under discussion. We will also indicate how a generalised version of Scanlon's notion of substantive responsibility can shed light not only on some apparent difficulties with justifying vicarious liability, but also on how the liable party's voluntary involvement in some kind of relation with the 
contributing party ultimately holds the key to a proper justification of the whole doctrine, broadly conceived.

Naturally, the case of the employer's vicarious liability for the employee's tort clearly done in the course of employment (such as an employee's negligent driving while delivering a wedding cake in time for the reception) is the easiest case to explain: the employee did something prohibited, something that falls within the scope of their employment, and the employer got voluntarily involved by hiring the employee and delegating certain tasks to them, in this case, to further their own interests.

Ascribing vicarious responsibility to an employer starts to be challenging when there is an employee's intentional wrongdoing, perhaps even a criminal conduct, as in the case of Bazley. Are we in principle capable of covering such examples? We believe that the answer is generally affirmative. This is so because it is rather openended how broadly the set of propositions within the scope of employment is understood. It might be that the societal goal of victim protection will establish that even sexual abuse unproblematically falls within the scope of employment.

While distinguishing employees from (in)dependent contractors has been usual practice, it is becoming increasingly difficult to do so (as an illustration, consider the two factually similar cases Ready Mixed Concrete (South East) Ltd $v$ Minister of Pensions and National Insurance. ${ }^{13}$ and Hollis $v$ Vabu ${ }^{14}$ that were judged differently, as discussed by Giliker 2010, pp. 73-75). Our general analysis allows for keeping employees distinct from independent contractors, but at the same time provides (in principle) for the possibility of ascribing vicarious responsibility also in the case of contractors. That is, nothing precludes us from applying our definition to the case of $A$ being voluntary involved in a contractual relation with $B$. This would also allow us to use a broader understanding of the scope of a relation in the case of employees, and a narrower one in the case of contractors.

The case of the borrower-lender relation can be easily subsumed under our definition. We would like to highlight that our definition allows for subtler judgements about liability than usual practice: for instance, if the vehicle was taken involuntarily, our definition tells that the owner should not be vicariously responsible for the driver's negligent driving.

The case of the parental carer-child relation is more challenging. To begin with, it might be useful to note that we are focusing on parental carers rather than parents simpliciter, and to contrast voluntary involvement with involuntary involvement. Concerning the latter, if one considers the extreme fictional example of a forced "parenthood" in the film Vivarium, one can hardly take the people raising the child to be responsible for the child's wrongdoings (we take it that its real-world counterpart perhaps requires further thought). Concerning the former point, as we stressed earlier, becoming a parental carer is usually a voluntary decision. It is thus possible to root responsibility in some voluntary decision of a liable party even in this case, however cautious one needs to be about the scope of this relation.

\footnotetext{
132 QB 497 (1968).

14 HCA 44 (2001).
} 
Let us now explain how Scanlon's notion of substantive responsibility can help to overcome some apparent problems with justifying vicarious responsibility. As indicated above, Scanlon argues that substantive responsibility and moral reaction responsibility do not stand and fall together (a drug addict might be responsible in the moral reaction sense while not being responsible in the sense of substantive responsibility). What we think is helpful in the present context is the mirror image of this example: when substantive responsibility can be ascribed while moral reaction responsibility perhaps should not. It is appropriate to ascribe substantive responsibility because this is what the (liable) agent owes to others, due to the previous choices they faced and the decisions they made (their voluntary involvement in certain relations and activities with the contributing party); but the action does not belong to the liable party, it is not their own, or in other words, they are not the contributing party (and thus should not bear the moral reaction responsibility). We believe this is extremely important, given that the liable party can be entirely faultless.

Let us highlight how the criterion of voluntary involvement solves the justification problem. Voluntary involvement in a relation of the relevant kind can be understood as a form of responsibility for others (for example, an employer is responsible for their employee), the burden of which the agent voluntarily agreed to bear. This involvement entails a risk that the time will come when an agent who got involved will have to face obligations and charges that result not only from their own actions, but also from certain actions of others (those that fall within the relevant scope). Now of course, this might seem prima facie suspicious: why would anyone agree to take such a risk? However, the upside of this practice cannot be underestimated, and this points to a feature that the present approach has in common with enterprise liability: while an agent who got voluntarily involved assumes the risk of bearing negative normative consequences, there are usually also many benefits involved. For example, employees work for the employer, they help them to achieve their goals and solve their problems; the employer often receives vicarious praise for their hard work, and so forth. While not so obvious in the case of being a parental carer or being the lender of a vehicle, there are some benefits included too. (Apart from vicarious responsibility in the negative sense, children bring happiness and a sense of fulfilment, as well as bringing vicarious praise to their parents. Meanwhile, the lender normally receives financial compensation, gratitude, or some service in return.) Nevertheless, in the present account the benefits only highlight the possible reasons why the liable party might be tempted to get voluntarily involved. These possible reasons are not (even partially) the source of justification - a voluntary decision of the liable party to get involved is. For this reason, this justification works not only for enterprises that gain profit, but also for the non-profit sector, as well as for other relations relevant to vicarious responsibility in which we can get involved. 


\section{Concluding Remarks}

In this paper, we have attempted to make sense of vicarious responsibility by proposing solutions to the problems of explicating and justifying it. We introduced a criterion for the liable party's voluntary involvement in a relation with the contributing party. We proposed a theoretical framework inspired by various contributions to the analysis of core aspects of vicarious responsibility which have been offered both in the legal and in the moral domain. Putting these ingredients together has allowed us to address the explication problem, which arises from the apparently contradictory understanding of vicarious responsibility, as well as the justification problem, which arises from the seemingly unfair practice of ascribing vicarious responsibility.

Our approach could be extended in many ways. For instance, one could provide a more detailed analysis of the different kinds of relations that count as forms of voluntary involvement. Here we just mentioned some examples of working agreements, parental relations and borrowing activities, to give a general idea. Similarly, one could provide a finer-grained treatment of the notion of causal contribution, which would prompt new questions related to the justification problem. Another important objective for future investigations is achieving a proper understanding of whether the justification of vicarious responsibility in the moral domain and in the legal domain can ultimately be regarded as analogous, as Cane proposes. Moreover, the phenomenon of vicarious praise seems to be both widespread and underexplored.

Acknowledgements We thank Maximilian Kiener and the referees for insightful comments on the paper and John Horden for the proofreading. The preprint of this paper was read at the "Roots of Responsibility" seminar (University College London) during Daniela Glavaničová's stay there funded by the National Scholarship Programme of the Slovak Republic and SAIA. We are grateful for the brilliant comments on the paper, as well as to the funding body. The work was also presented at the conference of the Slovak Philosophical Association. Daniela Glavaničová was supported by the Slovak Research and Development Agency under the contract no. APVV-17-0057, VEGA 2/0125/22 and by the University of Oxford project New Horizons for Science and Religion in Central and Eastern Europe funded by the John Templeton Foundation. The opinions expressed in the publication are those of the authors and do not necessarily reflect the view of the John Templeton Foundation. Matteo Pascucci was supported by the Štefan Schwarz Fund of the Slovak Academy of Sciences for the project "A fine-grained analysis of Hohfeldian concepts" and by VEGA 2/0125/22.

Author Contributions The contents of the article are the result of a joint research work of the two authors.

Open Access This article is licensed under a Creative Commons Attribution 4.0 International License, which permits use, sharing, adaptation, distribution and reproduction in any medium or format, as long as you give appropriate credit to the original author(s) and the source, provide a link to the Creative Commons licence, and indicate if changes were made. The images or other third party material in this article are included in the article's Creative Commons licence, unless indicated otherwise in a credit line to the material. If material is not included in the article's Creative Commons licence and your intended use is not permitted by statutory regulation or exceeds the permitted use, you will need to obtain permission directly from the copyright holder. To view a copy of this licence, visit http://creativecommons.org/licen ses/by/4.0/. 


\section{References}

Blatz, C. (1972). Accountability and answerability. Journal of the Theory of Social Behaviour, 2(2), $101-120$.

Brodie, D. (2006). The enterprise and the borrowed worker. Industrial Law Journal, 35(1), 87-92.

Brodie, D. (2007). Enterprise liability: Justifying vicarious liability. Oxford Journal of Legal Studies, 27(3), 493-508.

Cane, P. (2002). Responsibility in law and morality. Oxford and Portland: Hart Publishing.

Cane, P. (2016). Role responsibility. The Journal of Ethics, 20(1-3), 279-298.

Cane, P., \& Goudkamp, J. (2018). Atiyah's accidents, compensation and the law (9th ed.). Cambridge: Cambridge University Press.

Duff, R. A. (2009). Strict responsibility, moral and criminal. The Journal of Value Inquiry, 43(3), 295-313.

Giliker, P. (2010). Vicarious liability in tort: A comparative perspective. New York: Cambridge University Press.

Glavaničová, D. \& Pascucci, M. (2019). Formal analysis of responsibility attribution in a multimodal framework. In M. Baldoni, M. Dastani, B. Liao, Y. Sakurai, \& R. Zalila Wenkstern (Eds.), International conference on principles and practice of multi-agent systems (pp. 36-51). Springer: Cham.

Gray, A. (2018). Vicarious liability: Critique and reform. Oxford: Hart Publishing.

Hart, H. L. A. (1949). The ascription of responsibility and rights. Proceedings of the Aristotelian Society, 49, 171-194.

Levitt, A. (1922). Cause, legal cause and proximate cause. Michigan Law Review, 21(1), 34-62.

Magnet, J. (2015). Vicarious liability and the professional employee. Canadian Cases on the Law of Torts, 6, 208-226.

May, L. (1983). Vicarious agency and corporate responsibility. Philosophical Studies, 43(1), 69-82.

Murphy, J. (2004). The merits of Rylands v Fletcher. Oxford Journal of Legal Studies, 24(4), 643-669.

Neyers, J. W. (2005). A theory of vicarious liability. Alberta Law Review, 43(2), 287-326.

Oddie, G., \& Tichý, P. (1982). The logic of ability, freedom and responsibility. Studia Logica, 41(2-3), $227-248$.

Scanlon, T. M. (1998). What we owe to each other. Cambridge, MA: Harvard University Press.

Scanlon, T. M. (2015). Forms and conditions of responsibility. In R. Clarke, M. McKenna, \& A. M. Smith (Eds.), The nature of moral responsibility (pp. 89-111). New York: Oxford University Press.

Stevens, R. (2007). Torts and rights. Oxford: Oxford University Press.

Shultz, T. R., Jaggi, C., \& Schleifer, M. (1987). Assigning vicarious responsibility. European Journal of Social Psychology, 17(3), 377-380.

Weinrib, E. J. (2012). The idea of private law. Oxford: Oxford University Press.

Publisher's Note Springer Nature remains neutral with regard to jurisdictional claims in published maps and institutional affiliations. 